\title{
National Identity, International Visitors: Narration and Translation of the Taipei 228 Memorial Museum
}

\author{
Chia-Li Chen* Min-Hsiu Liao**
}

\begin{abstract}
Although many museums nowadays provide multilingual services, translations in museums have not received enough attention from researchers. The issue of how ideology is embedded in museum texts is translated is particularly underresearched. Since museums are often important sites for tourists to learn about a nation, translation plays a pivotal role in mediating how international visitors construct the host nation's identity. The translation of national identity is even more important when sensitive topics are dealt with, such as exhibitions of the past in memorial museums. This paper takes the Taipei 228 Memorial Museum as a case study to examine how Taiwanese identity is formatted in the Chinese text and reframed in the English translation. The current study found inconsistent historical perspectives embedded in both texts, particularly in the English translation. We argue that, without awareness of ideological assumptions embedded in translations, museums run the risk of sending unintended messages to international visitors.
\end{abstract}

Keywords: museum translation, memorial museum, national identity, narration, ideology

\section{Introduction}

This paper presents an interdisciplinary study which draws from museum, linguistic and translation studies to address the issue of how national identity is formatted in museum texts and reframed in their translations into a different language, with an attempt to shed some light on how museums present their exhibits to international visitors and how the mediation of translation plays a pivotal role in these visitors' constructions of the host nation's identity.

This research topic derives from two theoretical premises: museums display concrete objects which facilitate the imagination of national identity; and textual interpretation produced by the museums constructs an institutional view of national identity. This research further extends these arguments to a multilingual context and explores, from the perspective of critical discourse analysis, the potential for a different view of national identity to be embedded in the translations than in the original text.

Museum researchers and practitioners in general acknowledge how a bad translation can affect exhibitions. Ambrose and Paine (2006: 101), for example, comment that 'if you are getting labels translated into other languages, do try to get the translation done by a native speaker; a bad translation may make your visitors laugh, but it will not help them to understand your exhibition.' However, there remains a paucity of systematic linguistic analysis of how even subtle linguistic shifts in the translation can have an impact on how institutional views are embedded in texts. More often than not, translations are only assessed by their faithfulness or fluency, but the ideological implications of translations are unquestioned ${ }^{1}$. In this paper, we will demonstrate with examples from the Taipei 228 Memorial Museum how subtle linguistic shifts in the translated texts such as temporal references and naming can have an impact on the construction of Taiwanese identity. It is hoped that this paper will further stimulate muchneeded discussion on translation practice in museum studies, promoting a shift from viewing it as simply a neutral communicative tool to understanding it as an interpretive practice which contributes to the manner in which international visitors construct the host nation's identity. 
This paper begins by outlining the theoretical and methodological issues regarding how museums construct national identity and how this institutional perspective on identity is constructed through museum texts. It will then introduce the historical background behind the complicated issues related to Taiwanese identity, and the Taipei 228 Memorial Museum, followed by discussion of the findings and conclusions.

\section{Museums and the Imagination of National Identity}

There are a large volume of published studies discussing the role of museums in constructing national identity, and they acknowledge that how museums narrate or do not narrate history can influence how visitors perceive the identity of a nation (McLean 2005: 1). National museums are often seen as the concrete form of the fluid concept of identity -in which 'national cultural heritage was and is still being created, transformed and shaped into collective views' (Kaplan 1994: 1). Taking a historical perspective, MacDonald (2003: 3 ) explains that since museums have a long tradition of collecting significant 'cultural objects', they naturally became expressive sites of national identity after the emergence of the nation-state. In fact, the existence of a museum is in itself 'a performative utterance of having an identity' (MacDonald 2003: 3).

However, how is national identity 'expressed' or 'performed' in museums? Knell (2011) refers to Anderson's (2006/1983) idea that the nation is an imagined political community, and compares museums with theatres. Like theatres, museums are places where collections of objects are provided to stimulate visitors' imagination of the nation's identity. (Knell 2011:4). This making-believe in museums can easily be perceived by visitors as a convincing representation of reality 'based on a moral positioning manufactured through acts of professionalization, [so that] public and professionals alike continue to imagine the museum as neutral, authoritative and trustworthy; an accurate rendition of the world as it ought to be understood' (Knell 2011:4).

Crucial to this process of leading visitors to construct reality in certain ways is the interpretive role of museum texts. As McLean (1998: 244) puts it, a museum represents the culture of the nation through 'recounting stories about the artefacts of past cultures'. While objects may be vague and ambiguous, textual narratives can be more specific in promoting particular views, values and beliefs (Knell 2011: 7). Because museums are perceived as authoritative cultural institutions, textual interpretation often functions as 'the interface through which the authoritative knowledge of the museum/author/connoisseur could be delivered to the public' (Meszaros, Gibson, and Carter 2011: 44). To Knell (2011:7), in many modern narrative-based museums, interpretive texts 'have been carefully constructed to permit a singular public performance, a singular manifestation of the nation rather than the nation found through democratic negotiation.'

In the global context, museums are often important sites for international visitors to learn about a nation, and very often their visiting experience is mediated through texts translated into different languages. In fact, we argue that the ways in which museums deal with a delicate topic such as national identity in translated texts can be even more important than how they deal with it in the original text, because as Lidchi (1991: 166) asserts, visitors who come from other cultures may find it difficult to identify a common ground with the objects and will rely on the information provided in texts. In other words, international visitors are more likely to 'believe' the interpretation provided by museums to be reality than visitors who are from the country where the museum is located.

\section{Institutional Views Constructed in Museum Texts}

This paper follows Ravelli (2006: 1) by considering museum texts as 'the language produced by the [museum] institution, in written or spoken form, for the consumption of visitors, which contributes to interpretative practices within the institution'. Just like any other texts, museum texts are produced for a purpose, and involve a series of decisions. More often than not, the reasons behind these decisions are closely related to the nature of museums as social institutions, so museum texts need to reflect 'the wishes and ambitions, the intellectual or political or social or educational aspirations and preconceptions of the museum director, the curator, the scholar, the designer, the sponsor' (Vergo 1989: 3). Baxandall (1991: 38) argues even further that museum texts do not describe objects, but merely describe the exhibitors' thinking. 
Considering that museum texts are 'active agents in shaping opinions and identity' (Coxall 1994: 132), in this paper we chose to adopt the methodology of Critical Discourse Analysis (CDA), which sees language as a form of social practice, to explore how nationality is constructed by museums. The CDA framework has also been used by other researchers who explore institutional views in monolingual museum texts (e.g. Coxall 1994, Purser 2000, Ravelli 2006, and Hughes 2011).

CDA is a linguistic approach that emerged in the early 1990s and is based on the view that discourse - including written and spoken texts - is socially determined (refer to Wodak (2001) for a detailed review of CDA). Texts are constructed under the influence of their immediate situations, institutions and social structures; at the same time, the uses of texts can reinforce particular views of socio-historical and political ideology. In a museum context, for example, the construction of texts may be constrained by the exhibition space (situational), the political stance of the museum (institutional), and societal attitudes or legal policies regarding a certain issue (social). At the same time, museum texts guide visitors to interpret a particular social or political reality, such as the identity of a nation, and thus reinforce a particular ideology in the society. Important views of CDA are that texts (not words or sentences) should be regarded as the basic unit of communication, and texts cannot be understood apart from the situational, institutional and social context.

Considering that our paper addresses texts in the museum context, we find the focused questions in the seminal work of Coxall (1994), who was an experienced museum language consultant and researcher, particularly relevant and useful. In her analysis, the interface between texts and the wider context is explored step by step by answering four questions: What does the linguistic evidence indicate about the position of the writer? What were the writers saying? What were they choosing not to say? Who did they appear to be addressing? We find these questions straightforward guides to answering our research questions. Therefore, in the following discussion, we will first explore these four questions in detail in the context of memorial museums, and later show how these questions can be modified to suit our research data which include both source and translated texts.

In Coxall's (1994) model, Question 1 refers to examining the surface linguistic features that have potential to shape opinions, such as sensitive lexical choices. Question 2 and Question 3 are two sides of the same coin - what are museums (not) saying? To further narrow down the meaning of these questions, we refer to the four key questions for memorial museums to answer and respond proposed by Williams (2012: 97), including: Which groups suffered? Who was to blame? Are we/they still suffering? What needs to be done to right historical wrongs? For purposes of understanding the ideology being conveyed, what is not said is perhaps even more important than what is said. CDA adopts the view that text is created through a decision-making process, so 'many occurrences are significant by virtue of the other alternatives which might have occurred instead' (De Beaugrande and Dressler 1981: 35). This focus on what alternative language choices are left unchosen and what questions are left unanswered will be crucial in our data analysis. Regarding Question 4 on the issue of addressees in memorial museums, text writers need to bear in mind that visitors bearing different cultural and historical identities can respond differently to 'the cluster of ideas concerning personal culpability, victimhood, and future vigilance' (Williams 2012: 97).

Now we would like to extend Coxall's (1994) view on the relationship between language and ideology to the construction of translated museum texts, as a further layer of mediation in museum communication. If we accept the argument of CDA that language is socially determined, then it would be naïve to expect that the same underlying ideology and assumptions can be maintained when a text is translated into a different language, which is often rooted in a different society and culture. Therefore, shifts in meaning are inevitable in the process of translation, and even subtle shifts have the potential to alter the ideological assumption embedded in the source text. The implication of this argument is that museum practitioners should not take for granted that the translated text has the same meaning as the source text. Furthermore, any deviation of the target text from the source text should not be easily taken as an error or defect. Rather, the discrepancies between the source and the target texts should lead analysts to explore how the differences between the source and the translated texts can have an impact on the international visitors' perceptions of the exhibition. 
In our case study of the Taipei 228 Memorial Museum, we compare the source texts in Chinese and their translations in English. Thus, in terms of question four in Coxall's (1994) model, there are two addressees. The Chinese text mainly addresses the local visitors who are more likely to have some knowledge of the 228 Incident and are aware of the complexities of Taiwanese identity. On the other hand, the English translation is for English-speaking international visitors without knowledge of the Chinese language, and very likely with little knowledge of Taiwanese history and politics. Based on this assumption, we attempt to answer the other three questions by comparing the source text and the translation: 1) What does the linguistic evidence indicate about the position of the writer of the original text and the translator? 2) Were there any differences between what they were saying? 3) Were there any differences between what they were not saying?

\section{The 228 Incident and the Formation of Taiwanese Identities}

As discussed above, a nation can be understood as an imagined political entity. In the case of Taiwan, the concept of nation is even more peculiar and 'imagined' because it is 'a small island without nation-state status, with a history of multiple colonialisms, and living in the threatening shadow of a rising super power' (Shih 2003: 143). The ongoing political rivalry between Taiwan, officially known as the Republic of China (ROC), and mainland China, officially known as the People's Republic of China (PRC) is central to the construction of narratives of Taiwanese identities. The fact that Taiwan was ceded by the Qing dynasty of China to Japan after the first Sino-Japanese War in 1895 and subsequently was under Japanese colonization for fifty years (1895-1945) complicated the issue of Taiwanese identity even more.

The tension between Taiwan, People's Republic of China and Japan is probably most clearly manifested in the 228 Incident, the worst massacre of modern Taiwanese history. The incident occurred in Taiwan on 28 February 1947 and is thus called the 228 Incident. The year 1947 was two years after the Japanese colonial period ended, and Taiwan was reunited with China (under the control of a Nationalist government) after fifty years of separation. This reunification was at first welcomed by many people in Taiwan. However, just months after the provincial government headed by Governor Chen Yi was established in Taiwan, tensions between the Taiwanese and the mainlanders (new immigrants from China after 1945) began to rise and gradually led to frequent conflicts.

Chen (2003) characterizes the origin of the tension between the Taiwanese and the mainland Chinese as being closely related to the colonial experience of the Taiwanese. First, for the mainlanders, Japan was their enemy during the Second World War, but many Taiwanese were either forced or volunteered to join the Japanese army and fight against China during the Second World War. In this regard, Taiwan and China were enemies during the War. Therefore, the Governor-General Chen-Yi and many immigrant Chinese held the view that Taiwanese people were essentially Japanese, and needed to be re-educated. Taiwanese people quickly felt that they were not trusted by the mainlanders and were considered second-class citizens. This reality frustrated many Taiwanese people who had hoped that the end of colonization under a foreign regime meant equal political participation and more room for self-government. Further to the disappointment of Taiwanese people were the corruption and inefficiency of the provincial government. These conflicts between the two groups of people eventually led to the outbreak of the 228 Incident.

The immediate cause of the 228 Incident was that on 28 February 1947, monopoly bureau inspectors attempted to arrest a woman who sold untaxed cigarettes, and beat her unconscious. The brutal behaviour of the government officials angered people and fury at the new immigrants exploded among the Taiwanese. After a short period of upheaval, the government started negotiations with representatives of the people, who demanded the peaceful resolution of the Incident along with political reforms. However, while promising these demands GovernorGeneral Chen asked the central government to send more troops from China. As soon as the troops arrived in Taiwan, they started a massacre of Taiwanese people. In addition, people's representatives and others who spoke for the political reform were arrested. The Taipei 228 Memorial Museum (2011a: 64) estimates that between 18,000 and 28,000 people were killed or 'disappeared', although these figures are still debatable. 
Discussion of the Incident became taboo in Taiwanese society until the lifting of martial law in 1987. In 1995, Taiwanese President Lee Teng-Hui made a formal apology for the Incident, and declared 28 February a national holiday to commemorate it. In 1997, the Taipei 228 Memorial Museum was established on the site of a former radio station where the Incident occurred, and several other memorial museums were later founded elsewhere in Taiwan.

The 228 Incident has been interpreted and narrated by politicians from different parties and social groups in Taiwan with different ideologies, resulting in their constructing of their own versions of historical narratives, which are then used to construct different versions of Taiwanese identities. As the most tragic incident in Taiwan's modern history, the memory of this event has 'enhanced a sense of common suffering and imprinted a collective memory' and thus '228 became both the source and the most important point of reference for the formation of Taiwanese identity' (Fleischauer 2007: 375). How the stories of the 228 Incident have been told has also changed with time, when different interest groups have changed their interpretation as to what constitutes Taiwanese identity.

Broadly speaking, the memory of the 228 Incident has been constructed to reflect and reinforce two different historical perspectives of Taiwan: the Great China perspective and the Taiwan-centred perspective. For a long time the history of Taiwan has been narrated within the framework of the Great China Perspective, which emphasises the historical and cultural link between Taiwan and mainland China. However, since the 1970s, a Taiwan-centred narrative of history has emerged due to 'the trend toward more political openness, the opposition party's demand for "localization" or "Taiwanization", [and] the worldwide interest in "searching for one's roots"' (Hsiao 1994: 19). This view sees the influence of Chinese culture as only part of the whole of Taiwanese history, and highlights the uniqueness of Taiwan by emphasizing its multi-ethnic background, including its experiences of being colonized.

These two contesting historical perspectives provide frameworks for the narratives of historical events such as the 228 Incident, and in support of different views of national identities. Wu (2006: 17) comments on two divergent memories of the Incident in Taiwan: Taiwanese independence supporters see the Incident as a lesson from which to learn, i.e. a 'foreign regime' inevitably leads to tragedy, and, therefore, the Incident provides a legitimate reason for Taiwanese independence. On the other hand, those who adopt the Great China Perspective consider the 228 Incident and the following 36 years of martial law as an extension of the civil war in China. From this perspective, the 228 Incident was justified and should be left behind. In the analysis of our data, we pay particular attention to whether and how these two historical perspectives are constructed in the Chinese and the English texts.

\section{The Taipei 228 Memorial Museum}

Established on 28 February 1997, The Taipei 228 Memorial Museum is the first 228 museum in Taiwan. The museum was first developed by a private organization, The Taiwan Peace Foundation, commissioned by the Department of Civil Affairs of the Taipei City Council. The supervisory body of the museum was changed to the Department of Cultural Affairs in 19992000, the Taipei Region Development Institute in 2000-2003, and since 2003 has been back with the Department of Cultural Affairs. The museum houses a permanent exhibition on the 228 Incident, and also organizes special exhibitions related to the Incident. The permanent exhibition was redesigned in 2003 by another private organization, The New Taiwan Research Foundation.

The main language of the museum is Mandarin Chinese, but translations in English and Japanese are also available. In the following discussion, we will focus only on the English translation because the English translation has the potential to reach visitors from a wider spectrum of cultural and linguistic backgrounds than the Japanese version.

For visitors with no knowledge of Chinese, the museum provides translations for only limited text panels. Audio guides are also only on selected displayed objects. Alternatively, visitors can purchase a more detailed translated version of the guidebook to the museum from the museum shop for the price of 100 Taiwanese Dollars (about 2 British Pounds).

For the purpose of our research, the guidebook is chosen as the main data because the fact that the entire Chinese guidebook is translated allows us to examine systematic 
translation shifts, such as patterns of lexical choices or omissions. Such examination is not possible when only parts of the source texts are translated, as in the cases of the text panels and audio guides. However, we are fully aware that even limited translations in text panels and audio guides communicate with international visitors, and we are also cautious about possible inconsistencies in language uses in these three modes of communication. Therefore, after we identified significant trends of translation shifts in the guidebook, we further compared them with language use in the text panels and audio guides, in order to obtain a complete picture of multilingual communication in the museum.

The guidebook is published by the supervisory organization of the museum, the Department of Cultural Affairs of the Taipei City Council. The guidebook contains 76 pages, including a preface and eight chapters, following the order of the twelve exhibition rooms in the permanent exhibition (in some cases the content of two exhibition rooms are merged into one chapter). The content includes textual narratives and pictures of the displayed objects and the exhibition space. The preface of the guidebook expresses that the aim of the translated guidebooks is to help international visitors understand the exhibited objects better and have a deeper understanding of the 228 Incident. The guidebook interacts closely with the exhibition space, as can be illustrated by instructional sentences such as 'on the wall, we see the whitelettered names on a background' (Taipei 228 Memorial Museum 2011b: 50) or 'at the corner of the exhibition room, the wooden cases containing cigarettes of different brands' (Taipei 228 Memorial Museum 2011b: 40). These sentences clearly indicate that the guidebook is designed to guide visitors to walk through the exhibition.

We are aware that guidebooks, text panels, and audio guides each interact with exhibition spaces and visitors in different manners. Given the limited space in this paper, our focus is only on how linguistic choices in museum texts construct an institutional view of identity, but we do not attempt to speculate regarding how meanings are created through the interactions between texts, objects, and visitors, which would be a different research topic.

\section{Reshaping Taiwanese Identities: A Case Study of the Taipei 228 Memorial Museum}

The data analysis was carried out through the following steps: First, the English and the Chinese texts were closely compared and all translation shifts, i.e. changes in the target text as compared to the source text, were identified. Second, we left out one-off shifts. This is to ensure that we focused on systematic shifts rather than exceptional instances. Third, we related trends in translation shifts to the three questions: 1) What is the evidence of the position of the writer and the translator? 2) Are there any differences between what they are saying? 3) Are there any differences between what they were choosing not to say? Next, we brought in the historical-social context in relation to Taiwanese identities, and eventually categorized the trends of shifts under three themes: naming (who was suffering and who was to blame), the historical context (what is said and what is left unsaid), and whether we/they are still suffering. Due to space limitations, in the analysis we can only discuss one representative example in depth under each theme, but the implication of the selected examples goes beyond an individual and represents a trend. In the presentation of the examples below, ST stands for the source text; the bracketed passage immediately below is a literal translation of the source text by the authors for readers without knowledge of Chinese; and TT stands for the translated texts by the museum.

\section{Naming: Chinese versus Taiwanese?}

The 228 Incident was fundamentally an uprising of people involving those who were already in Taiwan before Taiwan was under the control of the Nationalist government and those who came with the Nationalist government to Taiwan after 1945. How these two groups are named can have a direct impact on how this Incident is interpreted because the way they are named answers the questions of which groups suffered and who was to blame. In examining our data, we find inconsistent, and potentially ideologically conflicting, instances of naming in Chinese and English. The naming choices between the guidebook, the text panels, and the audio guides are also inconsistent. Example 1 is an extract from the guidebooks. 


\section{Example 1}

(ST) 此外, 民眾也遷怒外省人, 濫施報復。走避不及的外省民眾遭到圍毆, 本省 籍民眾則受到巡邏憲兵、軍隊的槍擊或毆打, 全臺陷入大規模混亂狀態。

[Besides, the public took their anger out on wàishěngrén, and retaliated. Some wàishěngrén could not escape and were beaten by běnshěngrén. Běnshěngrén were shot or beaten by patrolling military police or troops. The entirety of Taiwan was in large-scale chaos.]

(TT) In addition, the public took their anger out on non-Taiwanese civilians, and retaliated. Some non-Taiwanese civilians were beaten by Taiwanese people; some Taiwanese people were shot or beaten by armed forces. Taiwan was in chaos.

In this passage describing the conflict, the opposing parties are named 本省人 (běnshěngrén) and 外省人 (wàishěngrén), literally translated as people from this province, and people from outside of the province. The terms have been conventionally used in Taiwan for a long time to refer to those who were already in Taiwan before 1945, and those who immigrated to Taiwan after Taiwan came under the control of the Nationalist government; particularly those who retreated to Taiwan with the Nationalist Party after it lost the war against the Communist Party.

It is worth noting that in other places in the guidebook, a more straightforward term "台 灣人民” (people of Taiwan) and references to the institution “國民政府” (Nationalist government) are used to narrate the socio-historical background. However, in the chapter entitled Outbreak of the 228 Incident, this pair of terms more loaded with historical ideology is used. In fact, these terms are rarely used in Taiwanese society now because they are considered to intensify tension between the two ethnic groups. We argue this naming choice in the Chinese guidebook is best understood in the historical and geographical sense of when the Incident took place.

The uses of Taiwanese and non-Taiwanese in the English translation are arguably more ambiguous, considering the current controversial political status of Taiwan. It is argued that 'the very term "Taiwanese" has been transformed from an ethnic term for "native Taiwanese" to a political term for "citizens of Taiwan"' (Fleischauer 2007: 387). In other words, in the contemporary context, the distinction between Taiwanese or non-Taiwanese often does not refer as much to the geographical boundary of the island but to political identity. For Englishspeaking readers, the term non-Taiwanese can also have the potential to be projected to the current division between the PRC and the ROC. Fleischauer (2007) argues that the 228 Incident has entered a new stage of interpretation whereby the mainland nationalist/native Taiwanese division is now interpreted as the PRC/ROC division - 'the 228 Incident as a weapon against the new foremost opponent of the Taiwan independence movement, namely the PRC and its military threat to Taiwan' (Fleischauer 2007: 392). He gives the example of the movement of the '228 Hand-in-Hand Rally' on 28 February 2004. On the eve of the presidential election, the pro-independence parties organized this event to form a human chain of more than 300 $\mathrm{km}$ across Taiwan, as a symbol to protect Taiwan from the 'outsiders', understood as the PRC in this case.

In this example from the guidebook, the linguistic strategy of naming in the Chinese text contributes to the construction of the Great China Perspective, i.e. seeing the 228 Incident as a civil war. The English translation is more ambiguous and has the potential to be interpreted as the Taiwan-Centred Perspective.

This passage also appears in the text panels and in the audio guides. The Chinese naming is consistent in the three modes, but the English translation in the text panels and the audio guides have the word mainlander, which places an emphasis on the geographical rather than political division. We have argued that the naming of the two groups of people is crucial to the interpretation of the Incident, and related to which historical framework is used, and ultimately how Taiwanese identity is constructed. However, in this case, the museum seems to have presented inconsistent or even conflicting views regarding Taiwanese identity to the English readers. 


\section{Contextual background: what is the role of the Japanese?}

We have previously explained that the tension between the Taiwanese and mainland China is closely related to Taiwan's fifty years of Japanese colonization, and therefore how the role of Japanese is narrated in this exhibition is central to the construction of Taiwanese identity. One linguistic feature instrumental in constructing the historical perspective is temporal reference. In the discussion of global conflict, Baker (2006: 112) observes that 'the meaning(s) and interpretive potential of a text or utterance ... are always decisively shaped by their spatial and temporal location'. This means that every story we recount from the temporal point of now-and-here is inevitably a projection of how we perceive the past.

During the period of Japanese colonization, Taiwanese society adopted the Japanese calendar, but this calendar is likely to be neither familiar to the contemporary Taiwanese nor to the readers of the English text. Example 2 is an illustration of the different presentation of dates in the Chinese and the English texts.

\section{Example 2}

(ST) 1921年(大正10年)1月30日, 由林獻堂、蔡惠如等178位臺灣知識分子, 向 日本帝國議會提出「設置臺灣議會」的請願。

[On January $30^{\text {th }}, 1921$ (10 $10^{\text {th }}$ year of Taisho period), 178 Taiwanese elites, including Lin Hsien-tang and Tsai Huei-ju, submitted to the Parliament of Imperial Japan, the Petition of the Establishment of the Taiwan Council.]

(TT) On January $30^{\text {th }}, 1921,178$ members of the Taiwanese elite led by Lin Hsien-tang and Tsai Huei-ju submitted the Petition of the Establishment of the Taiwan Council.

When recounting the events in the period of Japanese colonization, the Chinese text uses both the Western calendar and the traditional Japanese calendar, by which years were indicated by the length of an emperor's reign. In the English translation of the guidebook, the text panels, and the audio guides, only the western calendar is maintained. The omission can be regarded as a framing strategy which embeds the source text and the target text in a different temporal framework, and, consequently, different historical perspectives. The omission of the reference to the Japanese calendar is further coupled with omissions of the reference to the Parliament of Imperial Japan in this example and other references to Japanese colonization throughout the guidebook - for example, in Chapter 3, two paragraphs in the Chinese texts on the movement of Japanization during the colonial period are completely omitted in the English text.

Let us begin by examining the choice of including the Japanese calendar in the Chinese source text. For Taiwanese readers nowadays, the Japanese calendar has little meaning to them in terms of time reference. Therefore, the choice of including the Japanese calendar can also be regarded as a textual strategy to guide visitors to look back at the 228 Incident with the background of colonization in mind. As we have pointed out previously, the underlying cause of the outbreak of the 228 Incident is closely related to the experience of Japanese colonization. Taiwanese identity was entangled with the old and the new rulers, and also in the long journey of the campaign for democracy and human rights. This entanglement has lasted to the present day. Huang (2001) argues that for many Taiwanese people, to support the historical ideology of the Taiwan-centred Perspective is to hold the Japanese colonization in memory in a profound way, and by comparison, to see the ROC government, which came later, as a worse governor.

By discussing the role of the Japanese in the 228 Incident, the Chinese texts set the outbreak of the 228 Incident in a deeper historical context and explain how Taiwanese identity has been entangled with Japanese and Chinese identities. The Chinese text constructs the 228 Incident as an incident in the long journey of Taiwan's fight for democracy and human rights. The 228 Incident was not a standalone event, but part of Taiwan's continuous resistance to one colonizer after another. 
By contrast, the reference to the Japanese colonial background is largely left unsaid in the English translation, so the text has constructed a historical narrative of the 228 Incident in a vacuum without highlighting identity crisis as the underlying cause of the 228 Incident and setting Taiwanese people's fight for democracy and human rights in a wider temporal-spatial frame. This translation strategy not only undermines the complexities of the Taiwanese identity issue, but arguably does not provide the target reader with enough contextual information to allow them to understand how the Incident still has an impact on the current identity politics in Taiwan. The issue of continuity is further revealed in the next example.

\section{Past or future: has the Incident been justified?}

In the last chapter of the guidebook: The International Human Rights Forest, major translation shifts can be observed. The Chinese texts contain thirteen paragraphs, but the English texts only have seven paragraphs. In fact, some English paragraphs are almost a complete rewrite. The Chinese guidebook concludes the 228 Incident with an abstract and poetic style of writing, generalizing the specific Taiwanese experience and turning it into a universal human experience. The English translation omits the more abstract elements in the source text, and concludes the entire event by concentrating specifically on what Taiwanese people have achieved. Aconsistent pattern of more factual and brief English narratives has also been observed in the text panels and the audio guides. In the following, two examples from the guidebook will be presented. Example 3 represents the typical poetic narrative in the Chinese text. This passage does not exist in the English guidebook.

\section{Example 3}

(ST) 泥地裡種子發了芽。呼應整體展覽開場的民主主張, 已然紮在土地裡的根, 雖經風暴, 慢慢地長出新芽。人權的普世價值, 是和平的種籽。

[Buds have grown out of mud. The seed of democracy which echoes the opening of the exhibition has rooted in the ground. Although there are storms, the buds have grown out slowly. The universal value of human rights is the seed of peace.]

Example 3 demonstrates a poetic genre - it uses strategies of simile such as seeds growing out of mud as a comparison with the development of democracy and human rights, and used storms as a comparison with the violent political suppression. The last sentence presents the Taiwanese movement in line with the universal value that the world has been fighting for, rather than something specific to Taiwan. Overall, the Chinese text is aesthetic and expressive, and appeals to the emotion of the reader. By contrast, the English text is more informative, as illustrated in Example 4.

\section{Example 4}

(TT) Here, you can observe the development of Taiwan's democracy. The victims of the 228 Incident proposed local autonomy and free elections of municipal officials; these have all since been realized.

A salient difference is that the Chinese text emphasizes the continuity of Taiwan's democratic movement, whereas in the English text the 228 Incident is presented as a completed event. This may also explain why the majority of visitors' responses in English congratulate or admire Taiwan's 'achievement'. However, not all Taiwanese agree that the 228 Incident has been justified. Wu (2005: 2) maintains that 'transitional justice in Taiwan was pursued only by providing reparations to the victims but without tackling the greater issues of retributive justice against the perpetrators and of historical rectification'. In his view, there is nothing particular for the Taiwanese to be proud of from the perspective of transitional justice. By concluding the exhibition with a sentence like this, the English translation does not explain how the 228 Incident still has an impact on Taiwanese society to date, and why many Taiwanese people still demand more action from the government. In the construction of Taiwanese identity, the 
English text constructs the 228 Incident as a finished incident, and thus reinforces the view of the China Perspective, which sees the 228 Incident as a civil war.

Finally, although the Chinese texts present the 228 Incident as continuity, critically speaking, the poetic style of the narrative may also have its underlying assumption. What is left unsaid is the unfinished journey of transitional justice in Taiwan. The Chinese text has shifted the focus from the more concrete demands of the campaigners to a very superficial ideal. Beattie (2010: 48) warns that insufficient or unclear reflection by shifting expectations that remain unfulfilled, as in this example, can actually create more problems.

\section{Translation as a Bridge between National Identity and International Visitors}

This paper concludes by returning to the three questions we intended to ask at the beginning. The detailed linguistic analysis has revealed clear differences in how Taiwanese identity is constructed in the Chinese and the English texts. These differences result from different language choices which potentially entail different and sometimes conflicting assumptions of historical perspectives.

However, what is worrying is that not only are there discrepancies between the underlying ideology in the source and the translated texts, but the linguistic choices within the English translation also embody inconsistent assumptions of ideology. In the English guidebook, the choice of naming Taiwanese and non-Taiwanese seems to present a Taiwanese-Centred Perspective; but then in terms of temporal framing, the 228 Incident may be understood by English readers as a civil war and a justified Incident, which is more in line with the Great China Perspective. To make things more complicated, we also found inconsistencies in between translations in the guidebook, the text panels and the audio guides. This clearly indicated a lack of a rigorous reviewing procedure in the museum practice. The English translation in this museum is supposed to help international visitors who are often not familiar with Taiwan to learn more about the past and the present of the country, but with translations that send conflicting historical perspectives to the readers a clear picture of Taiwan may not be easily perceived.

The sensitive link between languages, ideology and exhibitions has been explored by museum researchers in a range of social topics such as prejudices against ethnicity, disability, immigrants and gender. Coxall (1994: 219), for instance, demonstrates that a seemingly neutral sentence such as "of all the trades, the slave trade was perhaps most profitable for London bankers" actually linguistically categorize the slaves as the same as inanimate objects. It may not be that museum text writers have a prejudiced view towards such topics, but discriminatory language can slip into museum texts unintentionally, mainly because museums often underestimate how ideological implications can be embedded in subtle uses of language. Coxall (1994: 138) highlights the need for writers to be aware of 'the process by which meanings are constructed and communicated', so that they can 'have more control over the unconsciously mediated messages in their texts'.

This paper argues that the same statement should be applied to the process of translation in museum exhibitions. The result of this study indicates that accumulation of systematic translation shifts can lead to a different narrative of national identity in the translated texts. Even the naming choice of just one word - mainlander or non-Taiwanese - has the potential to construct significantly different interpretations of the 228 Incident and project the Taiwanese identity in a different relation with the neighbouring PRC.

In the present global era, museums are important sites for a nation to show how it wants to be seen by others. After all, national identity is not only about how people of a nation 'imagine' their identities, but, perhaps more importantly, how a nation is perceived by others. Since the narration of the past plays a key role in constructing national identity, 'management of the past is thus not only a matter of national cohesion but also an international and economic affair' (Rivera 2008: 614). Narration mediated through translation thus needs to be scrutinized. This paper does not try to suggest that all language versions in the same museum exhibition should communicate the same point of view. However, museum staff should at least not have the innocent view that their commissioned translations are just the same as the source text, or that translations are transparent, neutral and impartial. In museum practice, this means that a more rigorous policies and procedure to commission and assess translations need to be in place. 
In conclusion, this paper has demonstrated a text-centred linguistic analysis on how views are constructed in texts and proved that translation should be researched as a separate agent from the source text. This finding will serve a base for future study on process-oriented investigation - e.g. how museums carry out translation, and how translations are assessed by museums; and on reception-oriented investigation - e.g. how visitors rely on translated texts may have different visiting experiences from others. Future studies in these directions will help provide a full picture on multilingual communication in museums.

Received: 30 March 2016

Finally accepted: 20 February 2017

\section{Notes}

1 Museum texts as research subject have also not received much attention from translation scholars. Among few studies on this topic, the emphasis tends to be describing linguistic shifts, but their implications on the exhibition theme, the institutional view, or the sociohistorical ideology is rarely discussed. A few exceptions are Deane-Cox (2014), Valdeón (2015) and Liao (2015), but to the best of our knowledge, translation as mediation between national identity and international visitors has not been explored.

\section{References}

\section{Primary Sources}

Taipei 228 Memorial Museum (2011a) The Permanent Exhibition of Taipei 228 Memorial Museum (Chinese Version), Taipei: Department of Cultural Affairs, Taipei City Government.

Taipei 228 Memorial Museum (2011b) The Permanent Exhibition of Taipei 228 Memorial Museum (English Version), Taipei: Department of Cultural Affairs, Taipei City Government.

\section{Secondary Sources}

Ambrose, T. and Paine, C. (2006) Museum Basics, $2^{\text {nd }}$ edition, London: Routledge.

Anderson, B. (2006 [1983]) Imagined Communities: Reflections on the Origins and Spread of Nationalism, London: Verso.

Baker, M. (2006) Translation and Conflict: A Narrative Account, London: Routledge.

Baxandall, M. (1991) 'Exhibition Intention: Some Preconditions of the Visual Display of Culturally Purposeful Objects', in Ivan Karp and Steven Lavine (eds) The Poetics and Politics of Museum Display, 33-41, Washington: Smithsonian Institution Press.

Beattie, A. (2010) 'Between Histories and Memories: Torgau's Memorial Museum for Germany's Short Twentieth Century', Museum and Society 8 (1) 37-55.

Chen, C-L. (2003) 'Interpreting History: Adults' Learning in the Taipei 228 Memorial Museum', Museological Review 9 16-29.

Coxall, H. (1994) 'Museum Text as Mediated Message', in Eilean Hooper-Greenhill (ed) The Educational Role of the Museum, 132-39, London: Routledge.

De Beaugrande, R. and Dressler, W.(1981) Introduction to text linguistics, London: Longman 
Deane-Cox, S. (2014) 'Remembering Oradour-sur-Glane: Collective Memory in Translation', Translation and Literature 23 272-83.

Fleischauer, S. (2007) 'The 228 Incident and the Taiwan Independence Movement's Construction of a Taiwanese Identity', China Information 21(3) 373-401.

Hsiao, H-H. (1994) 'A Search for Roots, Identity and Respect', Free China Review 44(2) 16-27.

Huang, C-H. (2001) 'The Yamatodamashi of Takasago Volunteers of Taiwan: A Reading of the Postcolonial Situation', in Harumi Befuand Sylvie Guichard-Anguis (eds) Globalizing Japan: Ethnography of the Japanese Presence in Asia, Europe, and America, 222-50, London: Routledge.

Hughes, S.A. (2011) 'The British Museum in Print: From National to Universal Museum', in Knell Simon et al. (eds) National Museums: New Studies from Around the World., 193-204, London: Routledge.

Kaplan, F. E. (1994) 'Introduction', in Flora Edouwaye Kaplan (ed) Museums and the Making of 'Ourselves': the Role of Objects in National Identity, 1-15, Leicester: Leicester University Press.

Knell, S. (2011) 'National Museums and The National Imagination', in Knell Simon et al. (eds) National Museums: New Studies from Around the World, 3-28, London: Routledge.

Liao, M-H. (2015) 'One Photo, Two Stories: Chinese Photos in British Museums', East Asian Journal of Popular Culture 1(2) 177-91.

Lidchi, H. (1991) 'The Poetics and Politics of Exhibiting Other Cultures', in Stuart Hall (ed) Representation: Cultural Representations and Signifying Practices, 151-220, London: SAGE publication.

Macdonald, S. (2003) 'Museums, National, Postnational and Transcultural Identities', Museum and Society 1(1) 1-16.

McLean, F. (1998) 'Museums and Construction of National Identity: A Review', International Journal of Heritage Studies 3(4) 244-52.

McLean, F. (2005) 'Museum and National Identity', Museum and Society 3(1) 1-4.

Meszaros, C., Gibson, T. and Carter, J. (2011) 'Interpretation and the Art Museum: Between the Familiar and the Unfamiliar', in Juliette Fritsch (ed) Museum Gallery Interpretation and Material Culture, 35-52, London: Routledge.

Purser, E. R. (2000) 'Telling Stories: Text Analysis in a Museum', in Eija Ventola (ed) Discourse and Community: Doing Functional Linguistics, 69-198, Tubingen: Gunter Narr Verlag.

Ravelli, L. (2006) Museum Texts: Communication Frameworks, London: Routledge.

Rivera, L. (2008) 'Managing "Spoiled" National Identity: War, Tourism, and Memory in Croatia', American Sociological Review 73 613-34.

Shih, S-M. (2003) 'Globalisation and the (In)significance of Taiwan', Postcolonial Studies, 6(2) 143-53. 
Vergo, P. (1989) 'Introduction', in Peter Vergo (ed) The New Museology, 1-5, London: Reaktion Books.

Williams, P. (2012) 'The Memorial Museum Identity Complex: Victimhood, Culpability, and Responsibility', in Bettina Messias Carbonell (ed) Museum Studies: An Anthology of Contexts, $2^{\text {nd }}$ edition, 97-115, Oxford: Wiley-Blackwell.

Valdeón, R. (2015) 'Colonial Museums in the US (un)translated', Language and Intercultural Communication, 15(3) 362-75

Wodak, R. (2001) 'What CDA is about: A Summary of its History, Important Concepts and its Developments', in Ruth Wodak and Michael Meyer (eds) Methods of Critical Discourse Analysis, 1-13, London: SAGE.

Wu, N-T. (2005) 'Transition without Justice or Justice without History: Transitional Justice in Taiwan', Taiwan Journal of Democracy 1(1) 77-102.

Wu, N-T. (2006) ‘轉型正義和歷史記憶：台灣民主化的未竟之業[Transitional Justice and Historical Memory: the Unfinished Mission of Taiwan's Democratization]', Reflexion 2 1-34.

* Chia-Li Chen is Director of the Graduate Institute of Museum Studies at the Taipei National University of the Arts. She is also a consultant of the National 228 Memorial Museum and a member of editorial board of several journals, including Museology Quarterly (Taiwan), Journal of Shanghai Science \& Technology Museum (China) and Museum Worlds (U.K.). Her research interests focus on three main areas: museums and contemporary social issues, especially the engagement and representation of the disabled and minority groups, museum, traumatic memories and human rights, and the history of community and literature museums.

Graduate Institute of Museum Studies,

Taipei National University of the Arts,

1 Hsueh-Yuan Road, Peitou, Taipei 112

Taiwan

Tel: +886 (0)2 28935414

Email: chiali21@hotmail.com

** Min-Hsiu Liao is Lecturer of Languages and Intercultural Studies at Heriot-Watt University. Her research interests are discourse and narrative analyses in translation studies. Her recent research projects explore how ideology and national identity are embedded in museum texts, and how they are translated for international visitors who are not familiar with the exhibited objects and the source culture.

Department of Languages and Intercultural Studies

Heriot-Watt University

Edinburgh, EH14 4AS

United Kingdom

Tel: +44 (0)1314514204

Email: m.liao@hw.ac.uk 